\title{
Multi-Objective Optimal Power Flow Problems Based on Slime Mould Algorithm
}

\author{
Sirote Khunkitti ${ }^{1, *(1)}$, Apirat Siritaratiwat ${ }^{2}$ and Suttichai Premrudeepreechacharn ${ }^{1}$ \\ 1 Department of Electrical Engineering, Faculty of Engineering, Chiang Mai University, \\ Chiang Mai 50200, Thailand; suttic@eng.cmu.ac.th \\ 2 Department of Electrical Engineering, Faculty of Engineering, Khon Kaen University, \\ Khon Kaen 40002, Thailand; apirat@kku.ac.th \\ * Correspondence: sirote.khunkitti@cmu.ac.th; Tel.: +66-868589799
}

check for updates

Citation: Khunkitti, S.; Siritaratiwat, A.; Premrudeepreechacharn, S. Multi-Objective Optimal Power Flow Problems Based on Slime Mould Algorithm. Sustainability 2021, 13, 7448. https://doi.org/ $10.3390 /$ su13137448

Academic Editors:

Maryam Bahramipanah and

Zagros Shahooei

Received: 17 May 2021

Accepted: 1 July 2021

Published: 2 July 2021

Publisher's Note: MDPI stays neutral with regard to jurisdictional claims in published maps and institutional affiliations.

Copyright: (c) 2021 by the authors. Licensee MDPI, Basel, Switzerland. This article is an open access article distributed under the terms and conditions of the Creative Commons Attribution (CC BY) license (https:// creativecommons.org/licenses/by/ $4.0 /)$.

\begin{abstract}
Solving the optimal power flow problems (OPF) is an important step in optimally dispatching the generation with the considered objective functions. A single-objective function is inadequate for modern power systems, required high-performance generation, so the problem becomes multiobjective optimal power flow (MOOPF). Although the MOOPF problem has been widely solved by many algorithms, new solutions are still required to obtain better performance of generation. Slime mould algorithm (SMA) is a recently proposed metaheuristic algorithm that has been applied to solve several optimization problems in different fields, except the MOOPF problem, while it outperforms various algorithms. Thus, this paper proposes solving MOOPF problems based on SMA considering cost, emission, and transmission line loss as part of the objective functions in a power system. The IEEE 30-, 57-, and 118-bus systems are used to investigate the performance of the SMA on solving MOOPF problems. The objective values generated by SMA are compared with those of other algorithms in the literature. The simulation results show that SMA provides better solutions than many other algorithms in the literature, and the Pareto fronts presenting multi-objective solutions can be efficiently obtained.
\end{abstract}

Keywords: multi-objective optimization; metaheuristic; optimal power flow; slime mould algorithm

\section{Introduction}

In the competitive electricity market, optimal power flow (OPF) is one of the important tools to optimally dispatch generation with the considered objective function while satisfying system constraints [1-3]. The OPF aims to find the best feasible values of control variables providing the best objective value. Generally, the objective function considered by power companies is to minimize generation costs in order to achieve the highest profits of power dispatch. Minimizing fuel cost is a direct way to decrease the generation cost while minimizing transmission line loss is another way to reduce power generation resulting in generation cost reduction. However, with the higher power generation of thermal plants for satisfying present higher load demand, a large amount of emission is emitted that causes pollution in the air [4]. Hence, three objectives consisting of fuel cost, emission, and transmission line loss are considered as part of the objective function to be minimized in the OPF problems of this study.

The OPF is a nonlinear, nonconvex, large-scale, and static programming problem [5] which has attracted an effort from many researchers to apply various methods to solve the problem. In the past, some traditional techniques such as quadratic programming [6], interior point method [7], and nonlinear programming [8] were used to solve the OPF problem. However, these algorithms are usually trapped in the local optima, which returns a low-quality solution, and requires a large amount of computational time. To overcome these weaknesses, many other optimization methods have been introduced. One of the methods are metaheuristic algorithms which have recently been the most popular methods 
adopted to successfully solve several optimization problems in different fields [9-17] including the OPF problem. Some of the metaheuristic algorithms, which have been used to solve single-objective OPF problem, are grasshopper optimization (GOA) [18], Harris hawks optimization (HHO) [18], salp swarm algorithm (SSA) [19], glow warm swarm optimization (GSO) [19], ant colony optimization (ACO) [20], and grey wolf optimizer (GWO) [21]. However, due to several necessary objective functions considered to be optimized, solving the single-objective OPF problem is inadequate in the present power systems. So, the OPF problem becomes a multi-objective OPF (MOOPF) problem which is more difficult and complex to be solved.

In the MOOPF problem, more than one independent objective is considered as the objective function; consequently, the number of optimal solutions as a trade-off between each objective is unlimited. These optimal solutions are called Pareto optimal solutions or Pareto fronts [22]. To solve the MOOPF problem, many methods have been introduced. For example, one of them converted the multi-objective problem into a single-objective problem so that a single-objective optimizer can be used. However, this technique requires weights for each objective resulting in the limitation of the available choices and the need for multiple runs [19]. Thus, to overcome these drawbacks, many algorithms such as hybrid dragonfly algorithm-particle swarm optimization (DA-PSO) [23], differential evolution (DE) [21], modified Gaussian bare-bones multi-objective imperialist competitive algorithm (MGBICA) [24], modified teaching-learning-based optimization (MTLBO) [25], and modified shuffled frog leaping algorithm (MSFLA) [26] have been proposed to solve the MOOPF problem, and the Pareto fronts were successfully generated. Besides, a multidimensional bi-objective optimization algorithm based on the branch-and-bound approach and trisection of hyper-rectangles which cover the feasible region is proposed for non-convex multi-objective optimization [27]. Moreover, visualization of the multidimensional results in the decision space can be important to gain insight into the Pareto optimal solutions. For example, the multidimensional scaling (MDS) and self-organizing maps (SOM) methods have proved their worth in solving multi-objective optimization (MOO) problems [28], and the recent application can be found in [29].

Despite many successes in solving different optimization problems including the MOOPF problem, several new optimization algorithms have still been proposed and qualified as high-performance algorithms such as GWO [30], whale optimization algorithm (WOA) [31], SSA [32], and HHO [33]. These newly proposed algorithms are expected to provide better solutions for different optimization problems than traditional algorithms. Slime mould algorithm (SMA) is a very recent algorithm proposed by Li, Shimin et al. [34], and it has received a huge of attractions by many researchers in various fields [35-37]. However, SMA has been rarely applied to solve the OPF problem [38] and never been investigated on solving the MOOPF problem. So that, this work proposes a method to solve the MOOPF problem in a power system based on SMA. A Pareto dominance concept is applied to the SMA, so that the SMA can store the non-dominated Pareto fronts for the MOOPF problems. A crowding mechanism is adopted to deal with the Pareto repository. The performance of the SMA has been evaluated for solving both single- and multi-objective OPF problems where fuel cost, emission, and transmission line loss are considered as part of the objective functions. IEEE 30-, 57-, and 118-bus systems were adopted to investigate the performance of the algorithm, and the simulation results were compared with many other algorithms in the literature.

The main contributions of this work are as follows:

1. A method to solve the MOOPF problem in the power systems based on SMA is proposed. The Pareto dominance concept is applied to the SMA in order to store non-dominated Pareto fronts, and the crowding mechanism is adopted to deal with the Pareto repository.

2. The SMA is adopted to solve single- and multi-objective optimal power flow problems in the IEEE 30-, 57-, and 118-bus systems. 
3. The performance of SMA is investigated in terms of fuel cost, emission, and transmission loss improvement, and the results are compared with those of many other algorithms in the literature.

The rest of the paper is divided as follows. Problem formulation of the MOO including objective functions and constraints is presented in Section 2. Section 3 introduces the SMA and its mathematical model. In Section 4, simulation results, comparison results, and discussions are provided. The conclusion of this work is finally given in Section 5.

\section{Problem Formulation}

The MOO aims to find an optimal set of decision variables on solving more than one objective functions while satisfying a set of equality and inequality constraints. The obtained solutions from the MOO problem have a trade-off between each considered objective function; thus, the number of the solutions is uncountable. The set of these solutions is traditionally called Pareto optimal solutions or Pareto fronts. The MOO problem can be mathematically modeled as the given equation.

$$
\min F=\left\{f_{1}(x, u), f_{2}(x, u), \ldots, f_{N_{o b}}(x, u)\right\}
$$

subject to

$$
\begin{aligned}
& g(x, u)=0 \\
& h(x, u) \leq 0
\end{aligned}
$$

where $f$ is a vector of the considered objective function to be optimized, $N_{o b}$ is the number of objective functions, $g(x, u)$ is the equality constraints, $h(x, u)$ is the inequality constraints, $x$ is a vector of state variables consisting of active power generation at the slack bus, voltage magnitudes at load buses, reactive power generations and apparent powers flowing in lines, and $u$ is a vector of control variables including active power generations except at slack bus, voltage magnitudes of generators, transformer tap ratios, and shunt compensation capacitor reactive powers.

\subsection{Objective Functions}

In this work, three objective functions comprising fuel cost, emission, and transmission line loss are considered as the objective functions in the MOOPF problem. Each objective is explained as follows:

\subsubsection{Fuel Cost}

The total fuel cost of the generated real power of the interconnected units is generally considered as part of the objective functions to be minimized for thermal plants. The total fuel cost can be represented by the quadratic function and formulated as the provided equation.

$$
f_{T C}(x, u)=\sum_{i=1}^{N_{g}}\left(a_{i} P_{g i}^{2}+b_{i} P_{g i}+c_{i}\right)
$$

where $f_{T C}$ is the total fuel cost function of generators $(\$ / \mathrm{h}), N_{g}$ is the number of generators, $a_{i}, b_{i}, c_{i}$ are fuel cost coefficients of the $i$ th generating unit, and $P_{g i}$ is the active power generation of the $i$ th generating unit.

\subsubsection{Emission}

The total emission function is taken into account to be minimized to reduce pollutions released by plants in the atmosphere. The summation of various types of emissions such 
as $\mathrm{SO}_{x}$ and $\mathrm{NO}_{x}$ are computed to represent the total emission function. The total emission function is calculated by the presented equation.

$$
f_{T E}(x, u)=\sum_{i=1}^{N_{g}}\left(\gamma_{i} P_{g i}^{2}+\beta_{i} P_{g i}+\alpha_{i}+\xi_{i} \exp \left(\lambda_{i} P_{g i}\right)\right)
$$

where $f_{T E}$ is the total emission function of generators (ton/h), and $\gamma_{i}, \beta_{i}, \alpha_{i}, \xi_{i}, \lambda_{i}$ are emission coefficients of the $i$ th generating unit.

\subsubsection{Transmission Line Loss}

To further reduce generation cost and active power generation, transmission line loss is aimed to be minimized. The line loss function is computed as follows:

$$
f_{T L}(x, u)=\sum_{k=1}^{N_{\text {line }}} g_{k}\left(V_{i}^{2}+V_{j}^{2}-2 V_{i} V_{j} \cos \left(\theta_{i j}\right)\right)
$$

where $f_{T L}$ is the total transmission line loss function (MW), $N_{\text {line }}$ is the number of transmission lines, $g_{k}$ is the conductance of the $k$ th transmission line, $V_{i}$ is the voltage magnitude at the $i$ th bus, $V_{j}$ is the voltage magnitude at the $j$ th bus, and $\theta_{i j}$ is the difference of voltage phase angle between buses $i$ and $j$.

\subsection{Constraints}

A set of equality and inequality constraints is satisfied while optimizing the considered objective functions.

\subsubsection{Equality Constraints}

The equality constraints of the OPF problem are active and reactive power balance equations formulated as the following equations.

$$
\begin{aligned}
P_{g i}-P_{d i} & =\sum_{j=1}^{N_{b u s}} V_{i} V_{j}\left(G_{i j} \cos \left(\theta_{i j}\right)+B_{i j} \sin \left(\theta_{i j}\right)\right) \\
Q_{g i}-Q_{d i} & =\sum_{j=1}^{N_{b u s}} V_{i} V_{j}\left(G_{i j} \sin \left(\theta_{i j}\right)-B_{i j} \cos \left(\theta_{i j}\right)\right)
\end{aligned}
$$

where $Q_{g i}$ is reactive power generations of the $i$ th generating unit, $P_{d i}$ and $Q_{d i}$ are active and reactive power demands at the $i$ th bus, respectively, $N_{b u s}$ is the number of buses, and Gij and Bij are the transfer conductance and transfer susceptance between buses $i$ and $j$, respectively.

\subsubsection{Inequality Constraints}

The inequality constraints of the OPF problem are set to satisfy system security as follows:

$$
\begin{gathered}
P_{\text {gimin }} \leq P_{g i} \leq P_{\text {gimax }} i=1,2, \ldots, N_{g} \\
Q_{\text {gimin }} \leq Q_{g i} \leq Q_{\text {gimax }} i=1,2, \ldots, N_{g} \\
V_{\text {gimin }} \leq V_{g i} \leq V_{\text {gimax }} i=1,2, \ldots, N_{g} \\
\left|S_{l i}\right| \leq S_{l i \max } \\
V_{L i \min } \leq V_{L i} \leq V_{L i \max } i=1,2, \ldots, N_{L} \\
Q_{c i \min } \leq Q_{c i} \leq Q_{\text {cimax }} i=1,2, \ldots, N_{c} \\
T_{i \min } \leq T_{i} \leq T_{\text {imax }} i=1,2, \ldots, N_{t}
\end{gathered}
$$


where $P_{\text {gimin }}$ and $P_{\text {gimax }}$ are the minimum and maximum active power generations of the $i$ th generating unit, respectively, $Q_{g i \text { min }}$ and $Q_{g i m a x}$ are the minimum and maximum reactive power generations of the $i$ th generating unit, respectively, $V_{g i \min }$ and $V_{g i \max }$ are the minimum and maximum voltage magnitudes of the $i$ th generating unit, respectively, $V_{g i}$ is the voltage magnitude of the $i$ th generating unit, $S_{l i}$ is the apparent power flowing in branch $i, S_{l i m a x}$ is the maximum apparent power flowing in branch $i, V_{L i \text { imin }}$ and $V_{L i m a x}$ are the minimum and maximum load bus voltage magnitudes at the $i$ th bus, respectively, $V_{L i}$ is the load bus voltage magnitude at the $i$ th bus, $Q_{c i \min }$ and $Q_{c i \max }$ are the minimum and maximum shunt compensation capacitors installed at the $i$ th bus, respectively, $Q_{c i}$ is the shunt compensation capacitor installed at the $i$ th bus, $T_{i \min }$ and $T_{i \max }$ are the minimum and maximum transformer tap ratios at the $i$ th bus, respectively, $T_{i}$ is the transformer tap ratio at the $i$ th bus, $N_{L}$ is the number of load buses, $N_{c}$ is the number of shunt compensation capacitors, and $N_{t}$ is the number of transformers.

\subsubsection{Constraint Handling}

The inequality constraints of the state variables which are uncontrollable are merged into the penalized objective function to ensure that these variables are maintained within their limits. The objective function is then penalized as the following equation [26].

$$
J(x, u)=f(x, u)+K_{P}\left(P_{g s l a c k}-P_{\text {gslack }}^{\lim }\right)^{2}+K_{V} \sum_{i=1}^{N_{L}}\left(V_{L i}-V_{L i}^{\lim }\right)^{2}+K_{Q} \sum_{i=1}^{N_{\text {line }}}\left(Q_{g i}-Q_{g i}^{\lim }\right)^{2}+K_{S} \sum_{i=1}^{N_{\text {line }}}\left(S_{l i}-S_{l i}^{\lim }\right)^{2}
$$

where $J(x, u)$ is the penalized objective function, and $K_{p}, K_{Q}, K_{V}$, and $K_{s}$ are the penalty factors for the real power generation limit violation at the slack bus, reactive power generation limit violation, load bus voltage violation, and the line apparent power flow violation, respectively. $P_{g s l a c k}^{\lim }, V_{L i}^{\lim }, Q_{g i}^{\lim }$, and $S_{l i}^{\lim }$ are the limit values of the real power generation at the slack bus, reactive power generation, load bus voltage, and line apparent power flow, respectively, defined as the equations below.

$$
\begin{gathered}
P_{g s l a c k}^{\lim }=\left\{\begin{array}{ccc}
P_{g s l a c k}^{\max } & \text { if } & P_{\text {gslack }}>P_{\text {gslack }}^{\max } \\
P_{\text {gslack }} & \text { if } & P_{\text {gslack }}^{\min }<P_{\text {gslack }}<P_{\text {gslack }}^{\max } \\
P_{g s \text { slack }}^{\min } & \text { if } & P_{\text {gslack }}<P_{g \text { slack }}^{\min }
\end{array}\right. \\
V_{L i}^{\lim }=\left\{\begin{array}{ccc}
V_{L i}^{\max } & \text { if } & V_{L i}>V_{L i}^{\max } \\
V_{L i} & \text { if } & V_{L i}^{\min }<V_{L i}<x^{\max } \\
V_{L i}^{\min } & \text { if } & V_{L i}<V_{L i}^{\min }
\end{array}\right. \\
Q_{g i}^{\lim }=\left\{\begin{array}{ccc}
Q_{g i}^{\max } & \text { if } & Q_{g i}>Q_{g i}^{\max } \\
Q_{g i} & \text { if } & Q_{g i}^{\min }<Q_{g i}<Q_{g i}^{\max } \\
Q_{g i}^{\min } & \text { if } & Q_{g i}<Q_{g i}^{\min }
\end{array}\right. \\
S_{l i}^{\lim }=\left\{\begin{array}{ccc}
S_{l i}^{\max } & \text { if } & S_{l i}>S_{l i}^{\max } \\
S_{l i} & \text { if } & S_{l i}<S_{l i}^{\max }
\end{array}\right.
\end{gathered}
$$

\section{Slime Mould Algorithm (SMA)}

The SMA was recently proposed by Li, Shimin et al. [34] based on the behavior of slime mould in nature. Slime mould searches for food, encircles it, and releases enzymes to digest it. The slime mould characteristics can be explained through three main steps, consisting of approaching food, wrapping food, and oscillating, mathematically formulated as the following subsections. 


\subsection{Approach Food}

To approach food, the slime mould follows the smell in the air which can be modeled as the given equation.

$$
X(t+1)=\left\{\begin{array}{c}
X_{b}(t)+v b \cdot\left(W \cdot X_{A}(t)-X_{B}(t)\right), r<p \\
v c \cdot X(t), r \geq p
\end{array}\right.
$$

where $X$ is the slime mould position, $X_{b}$ is the current position with the highest smell intensity (food position), $X_{A}$ and $X_{B}$ are two randomly chosen individuals from slime mould, $t$ is the current iteration, $r$ is a uniformly randomly generated value in the range of $[0,1], W$ is the adaptive weight of slime mould, $v b$ is a uniformly generated value in the range of $[-a, a], v c$ is a uniformly generated parameter in the range of $[-b, b]$ where $b$ is linearly decreased from 1 to 0 according to the iteration $(b=1-t$ /MaxIter), and $p$ is the probability index dynamically changed according to the following equation.

$$
p=\tanh |S(i)-D F|
$$

where $i=1,2, \ldots, n, n$ is the number of population, $S(i)$ is the fitness value of $X$, and $D F$ is the best fitness obtained so far. To find $v b$, the parameter a is computed by the presented equation.

$$
a=\operatorname{arctanh}\left(-\left(\frac{t}{\text { MaxIter }}\right)+1\right)
$$

where MaxIter represents the maximum iteration. The adaptive weight $(W)$ to simulate the process of generating positive and negative feedbacks of the propagation wave of slime mould can be computed as follows:

$$
W(\text { SmellIndex }(i))=\left\{\begin{array}{c}
1+r \cdot \log \left(\frac{b F-S(i)}{b F-w F}+1\right), \text { first half of population } \\
1-r \cdot \log \left(\frac{b F-S(i)}{b F-w F}+1\right), \text { other half of population } \\
\text { Smell Index }=\operatorname{sort}(S)
\end{array}\right.
$$

where $b F$ is the best fitness provided in the current iteration, $w F$ is the worst fitness provided in the current iteration, and Smellindex is the sequence of the sorted fitness values.

\subsection{Wrap Food}

From the approaching food process, the slime mould changes the search process according to the concentration of food. When the food concentration is poor, the weight of the area is decreased, when the food concentration is satisfied, the weight of the area will be increased. However, to improve the exploration phase of the SMA, the location of slime mould can be updated by the following equation.

$$
X^{*}(t+1)=\left\{\begin{array}{c}
\text { rand } \cdot(u b-l b)+l b, r<z \\
X_{b}(t)+v b \cdot\left(W \cdot X_{A}(t)-X_{B}(t)\right), r<p \\
v c \cdot X(t), r \geq p
\end{array}\right.
$$

where $u b$ and $l b$ are the upper and lower limits of the decision variables, rand is the uniformly randomly generated value in the range of $[0,1]$, and $z$ is set at 0.03 as it is the best value investigated in [34].

\subsection{Oscillation}

The parameters $W, v b$, and $v c$ in the above equations are used to simulate the variations of slime mould when the process of food-finding is operated. $W$ mathematically expresses the oscillation frequency of slime mould to improve the slime mould performance for selecting the best food source. When the slime mould discovers high-concentration food, 
they approach food faster, and when the food concentration is low, the slime mould more slowly approaches food.

From Equation (23), $v b$ randomly oscillates in the range of $[-a, a]$ and eventually tends to zero when the iteration is increased. In addition, $v c$ randomly oscillates between $[-1,1]$ and gradually reaches zero with the increase of iteration. These two parameters simulate the behavior of slime mould to discover a better food source. Although a high-quality food source is discovered, slime mould still separates some of their parts to explore more areas in order to find a higher-quality food source and avoid trapping in the local optima.

For the MOOPF problems where the considered objective functions conflict with each other and the results are a trade-off between each objective, the traditional computations require a large amount of computational effort and time. The variation of the random search can overcome this drawback; thus, the SMA is used to solve the MOOPF problems. The Pareto dominance concept is applied to the SMA to keep the trade-off between the considered objectives that is the Pareto fonts in the repository [39]. The non-dominated sorting and the crowding mechanism are adopted to deal with the full repository [40]. The process of the SMA for solving MOOPF problems can be described in the Pseudo-code expressed in Algorithm 1 and the flowchart presented in Figure 1.

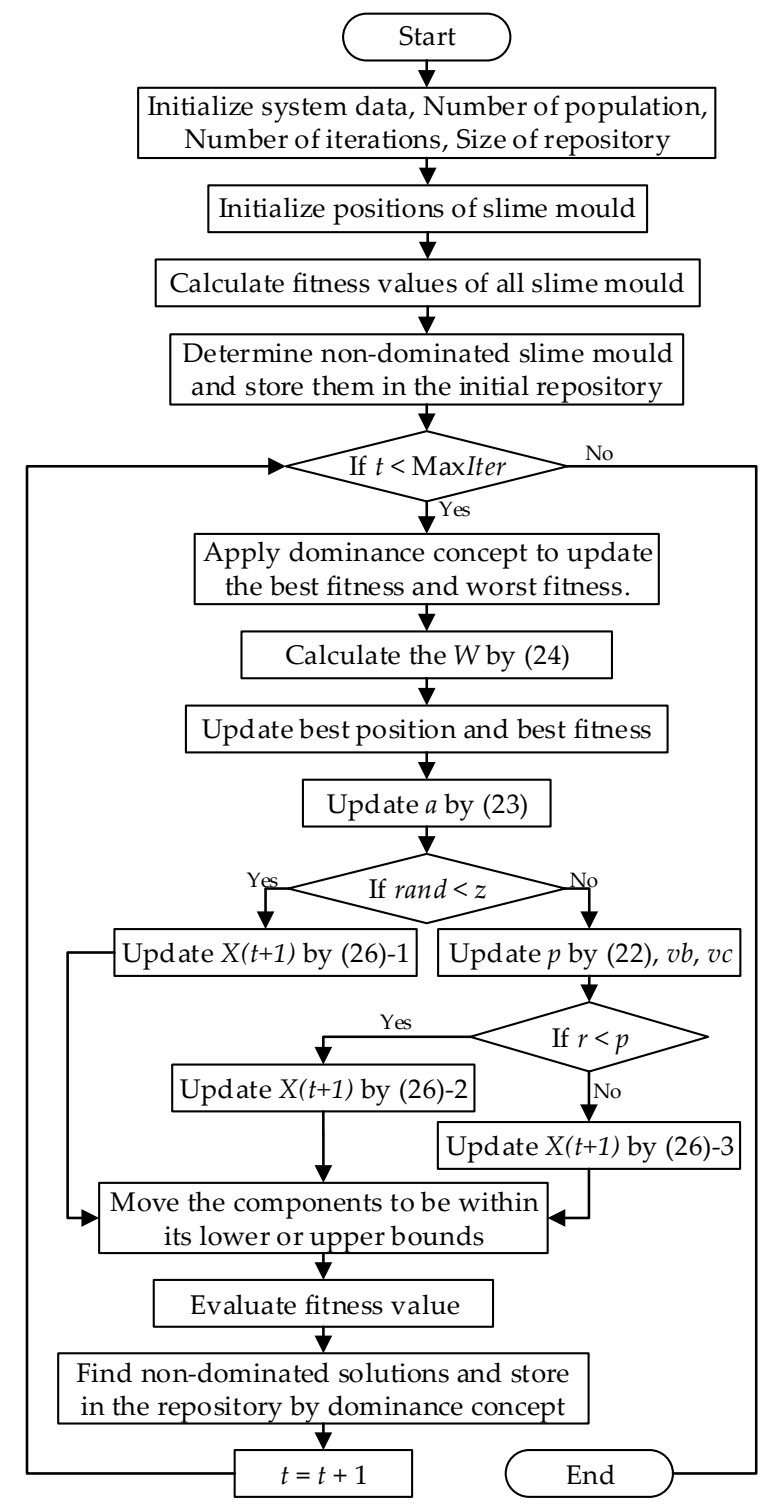

Figure 1. Flow chart of slime mould algorithm (SMA) for solving multi-objective optimal power flow (MOOPF) problems. 


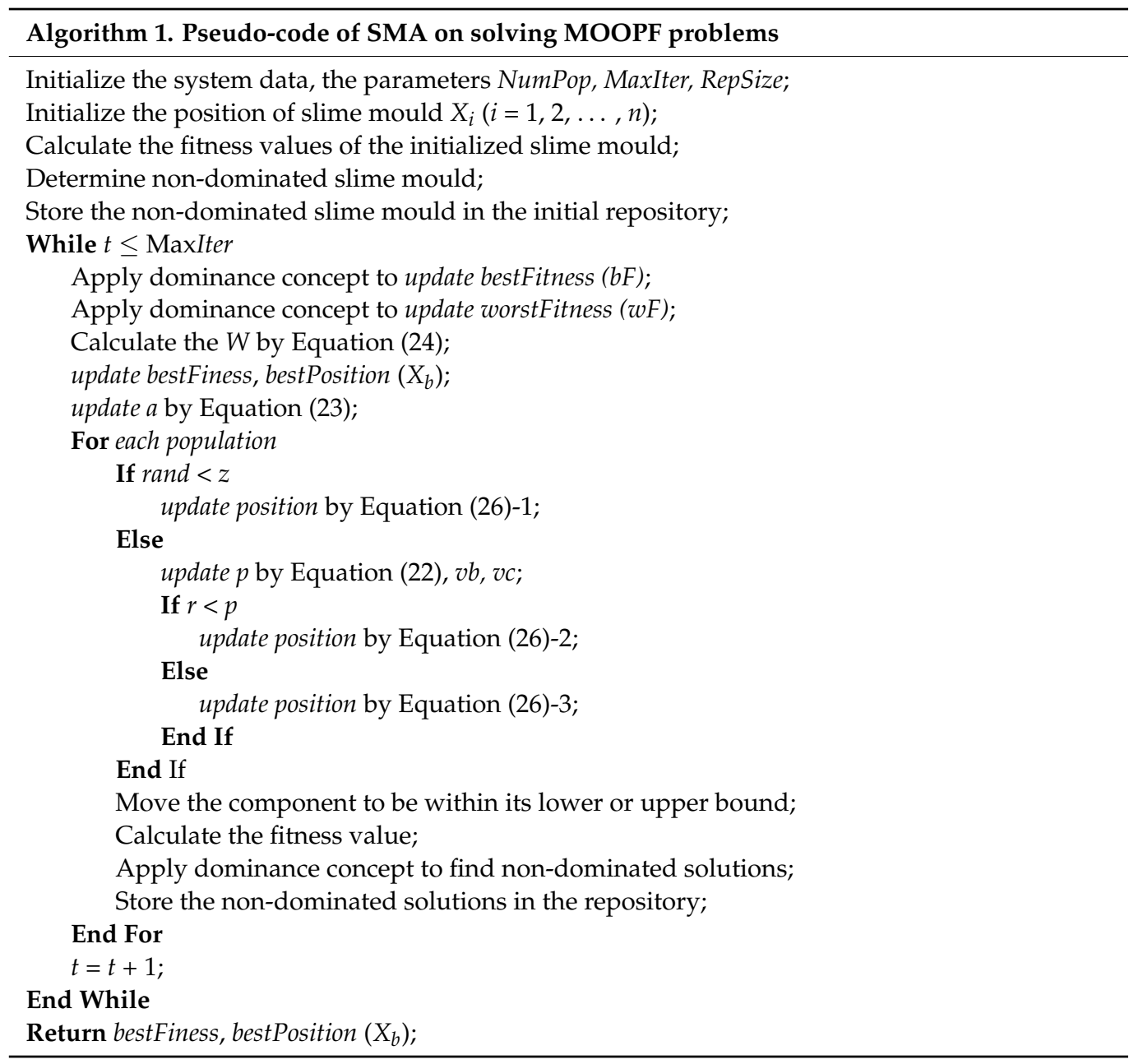

\section{Simulation Results and Discussion}

The SMA was applied to solve both single-objective and multi-objective OPF problems in the IEEE 30-, 57-, and 118-bus systems to investigate its performance in terms of fuel cost, emission, and transmission loss reductions where 14 different cases shown in Table 1 were evaluated. The simulation was operated in MATLAB. The data of the test systems and the results investigated by the SMA for solving single- and multi-objective OPF problems are presented in the following subsections.

Table 1. Case studies investigated in this work.

\begin{tabular}{ccc}
\hline Case Number & Objective Functions & Systems \\
\hline Case 1 & Fuel Cost & IEEE 30-bus \\
Case 2 & Emission & IEEE 30-bus \\
Case 3 & Line Loss & IEEE 30-bus \\
Case 4 & Fuel Cost, Emission & IEEE 30-bus \\
Case 5 & Fuel Cost, Line Loss & IEEE 30-bus \\
Case 6 & Emission, Line Loss & IEEE 30-bus \\
Case 7 & Fuel Cost, Emission, Line Loss & IEEE 30-bus \\
Case 8 & Fuel Cost & IEEE 57-bus \\
Case 9 & Emission & IEEE 57-bus \\
Case 10 & Line Loss & IEEE 57-bus \\
Case 11 & Fuel Cost, Emission & IEEE 57-bus \\
Case 12 & IEEE 57-bus \\
Case 13 & Fuel Cost & IEEE 118-bus \\
Case 14 & Fuel Cost, Line Loss & IEEE 118-bus \\
\hline
\end{tabular}




\subsection{IEEE 30-Bus System}

The IEEE 30-bus system was applied to evaluate the performance of the SMA on solving the OPF problems. This system included six generators, four transformers, and 41 transmission lines. The system active and reactive power demands were 283.4 MW and 126.6 MVAR, respectively. The detailed data and the line diagram of the system can be found in [41]. For this system, the population number, maximum iteration number and size of the repository were all set at 100. Cases 1-7 including single- and multi-objective OPF problems were investigated in this system.

The performance of the SMA was firstly evaluated on solving single-objective OPF problems where fuel cost, emission and transmission loss were individually considered as the objective function defined as cases $1-3$, respectively. The simulation results including control variables, slack bus active power, fuel cost, emission, and transmission loss of each case are presented in Table 2.

Table 2. Simulation results of the SMA on solving single-objective optimal power flow (OPF) problem in the IEEE 30-bus system.

\begin{tabular}{cccc}
\hline Variables & Case 1 & Case 2 & Case 3 \\
\hline$P_{g 2}(\mathrm{MW})$ & 48.8501 & 67.6666 & 80.0000 \\
$P_{g 5}(\mathrm{MW})$ & 21.5222 & 50.0000 & 50.0000 \\
$P_{g 8}(\mathrm{MW})$ & 22.1311 & 35.0000 & 35.0000 \\
$P_{g 11}(\mathrm{MW})$ & 12.2063 & 30.0000 & 30.0000 \\
$P_{g 13}(\mathrm{MW})$ & 12.0000 & 40.0000 & 40.0000 \\
$V_{g 1}$ (p.u.) & 1.0500 & 1.0500 & 1.0500 \\
$V_{g 2}$ (p.u.) & 1.0381 & 1.0458 & 1.0479 \\
$V_{g 5}$ (p.u.) & 1.0110 & 1.0274 & 1.0292 \\
$V_{g 8}$ (p.u.) & 1.0194 & 1.0346 & 1.0367 \\
$V_{g 11}$ (p.u.) & 1.1000 & 1.1000 & 1.1000 \\
$V_{g 13}$ (p.u.) & 1.0999 & 1.0137 & 1.0158 \\
$T_{6-9}$ (p.u.) & 0.9973 & 1.0137 & 1.0158 \\
$T_{6-10}$ (p.u.) & 0.9000 & 0.9000 & 0.9000 \\
$T_{4-12}$ (p.u.) & 1.0157 & 1.0110 & 1.0099 \\
$T_{27-28}$ (p.u.) & 0.9403 & 0.9531 & 0.9530 \\
$Q c_{10}$ (MVar) & 20.8943 & 4.3266 & 26.4703 \\
$Q c_{24}$ (MVar) & 20.9865 & 10.4775 & 0.6313 \\
$P_{g 1}$ (MW) & 176.2134 & 61.1709 & 51.6976 \\
\hline Fuel Cost (\$/h) & $\mathbf{8 0 2 . 5 4 4 9}$ & 945.0454 & 968.1335 \\
Emission (ton/h) & 0.363552 & $\mathbf{0 . 2 0 4 8 8 7}$ & 0.207294 \\
Loss (MW) & 9.5232 & 3.4375 & 3.2975 \\
\hline
\end{tabular}

\subsubsection{Case 1: Fuel Cost Minimization}

To verify the performance of the SMA on solving the OPF problem by considering fuel cost as the objective function, the simulation results of the SMA for case 1 are compared with those of many other algorithms in the literature, such as particle swarm optimization (PSO) [18], multi-verse optimization (MVO) [18], GOA [18], HHO [18], ACO [20], evolutionary programming (EP) [42], stochastic genetic algorithm (SGA) [43], and evolutionaryprogramming-based optimal power flow (EP-OPF) [44] as shown in Table 3. 
Table 3. Comparison results of the SMA with other algorithms for case 1.

\begin{tabular}{|c|c|c|c|c|c|c|c|c|c|c|}
\hline Algorithms & $P_{g 1}(\mathrm{MW})$ & $P_{g^{2}}(\mathrm{MW})$ & $P_{g^{5}}(\mathrm{MW})$ & $P_{g^{8}}(\mathrm{MW})$ & $P_{g 11}(\mathrm{MW})$ & $P_{g 13}(\mathrm{MW})$ & Cost (\$/h) & $\begin{array}{c}\text { Emission } \\
\text { (ton/h) }\end{array}$ & Loss (MW) & Time (s) \\
\hline PSO [18] & - & 31.9013 & 15.0000 & 10.0000 & 29.9591 & 12.0000 & 828.1315 & - & 8.3502 & - \\
\hline MVO [18] & - & 51.1890 & 21.3110 & 21.1730 & 22.6990 & 16.5870 & 810.9011 & - & 7.6800 & - \\
\hline GOA [18] & - & 48.0194 & 20.9145 & 20.2342 & 15.7260 & 13.5828 & 809.7410 & - & 10.0900 & - \\
\hline HHO [18] & - & 47.4072 & 17.3766 & 17.8064 & 13.1780 & 17.1314 & 804.1407 & - & 7.9700 & - \\
\hline ACO [20] & 181.9450 & 47.0010 & 21.4596 & 21.4460 & 13.2070 & 12.0134 & 802.5780 & 0.382000 & 9.8520 & - \\
\hline $\mathrm{EP}[42]$ & 173.8480 & 49.9980 & 21.3860 & 22.6300 & 12.9280 & 12.0000 & 802.6200 & 0.357217 & 9.3900 & 51.40 \\
\hline SGA [43] & 179.3670 & 44.2400 & 24.6100 & 19.9000 & 10.7100 & 14.0900 & 803.6990 & 0.371129 & 9.5177 & - \\
\hline EP-OPF [44] & 175.0297 & 48.9522 & 21.4200 & 22.7020 & 12.9040 & 12.1035 & 803.5710 & 0.360125 & 9.7114 & - \\
\hline SMA & 176.2134 & 48.8501 & 21.5222 & 22.1311 & 12.2063 & 12.0000 & 802.5449 & 0.363552 & 9.5232 & 60.09 \\
\hline
\end{tabular}

\subsubsection{Case 2: Emission Minimization}

In case 2, emission was selected as the objective function. The simulation results provided by the SMA are compared with those of HHO [19], SSA [19], WOA [19], moth flame (MF) [19], GSO [19], ACO [20], Gaussian bare-bones multi-objective imperialist competitive algorithm (GBICA) [24], teaching-learning-based optimization (TLBO) [25], MTLBO [25], shuffle frog leaping algorithm (SFLA) [26], MSFLA [26], genetic algorithm (GA) [26], improved particle swarm optimization (IPSO) [39], differential search algorithm (DSA) [45], and hybrid modified PSO-SFLA (HMPSO-SFLA) [46] as given in Table 4.

Table 4. Comparison results of the SMA with other algorithms for case 2.

\begin{tabular}{|c|c|c|c|c|c|c|c|c|c|c|}
\hline Algorithms & $\begin{array}{c}P_{g 1} \\
(\mathrm{MW})\end{array}$ & $P_{g^{2}}(\mathrm{MW})$ & $P_{g_{5}}(\mathrm{MW})$ & $P_{g 8}(\mathrm{MW})$ & $P_{g 11}(\mathrm{MW})$ & $P_{g 13}(\mathrm{MW})$ & Cost $(\$ / h)$ & $\begin{array}{c}\text { Emission } \\
\text { (ton/h) }\end{array}$ & $\begin{array}{l}\text { Loss } \\
\text { (MW) }\end{array}$ & $\underset{\text { (s) }}{\text { Time }}$ \\
\hline HHO [19] & 60.9900 & 70.9800 & 50.0000 & 35.0000 & 30.0000 & 40.0000 & 950.9800 & 0.285000 & 3.5700 & 56.00 \\
\hline SSA [19] & 61.0200 & 70.9500 & 50.0000 & 35.0000 & 30.0000 & 40.0000 & 950.9300 & 0.295000 & 3.6000 & 62.00 \\
\hline WOA [19] & 61.0800 & 70.8900 & 50.0000 & 35.0000 & 30.0000 & 40.0000 & 950.8200 & 0.295000 & 3.5710 & 62.00 \\
\hline MF [19] & 61.0200 & 70.9500 & 50.0000 & 35.0000 & 30.0000 & 40.0000 & 950.9300 & 0.295000 & 3.5720 & 61.00 \\
\hline GSO [19] & 60.9300 & 71.1200 & 50.0000 & 34.9300 & 30.0000 & 40.0000 & 951.1300 & 0.296000 & 3.5710 & 57.00 \\
\hline $\mathrm{ACO}[20]$ & 64.3720 & 72.1604 & 49.5438 & 32.9099 & 28.6113 & 39.7390 & 945.5870 & 0.221000 & 3.9368 & - \\
\hline GBICA [24] & 64.3125 & 67.4938 & 50.0000 & 35.0000 & 29.9924 & 40.0000 & 944.6516 & 0.204900 & 3.3987 & - \\
\hline TLBO [25] & 63.5221 & 68.7345 & 49.9931 & 34.9894 & 29.9824 & 39.9801 & 947.4392 & 0.205030 & 3.8016 & - \\
\hline MTLBO [25] & 64.2924 & 67.6250 & 50.0000 & 35.0000 & 30.0000 & 40.0000 & 945.1965 & 0.204930 & 3.5174 & - \\
\hline SFLA [26] & 64.4840 & 71.3807 & 49.8573 & 35.0000 & 30.0000 & 39.9729 & 960.1911 & 0.206300 & 7.2949 & - \\
\hline MSFLA [26] & 65.7798 & 68.2688 & 50.0000 & 34.9999 & 29.9982 & 39.9970 & 951.5106 & 0.205600 & 5.6437 & - \\
\hline GA [26] & 78.2885 & 68.1602 & 46.7848 & 33.4909 & 30.0000 & 36.3713 & 936.6152 & 0.211700 & 9.6957 & - \\
\hline IPSO [39] & 67.0400 & 68.1400 & 50.0000 & 35.0000 & 30.0000 & 40.0000 & 954.2480 & 0.205800 & 5.3620 & - \\
\hline DSA [45] & 64.0725 & 67.5711 & 50.0000 & 35.0000 & 30.0000 & 40.0000 & 944.4086 & 0.205826 & 3.2437 & - \\
\hline HMPSO-SFLA [46] & 64.8148 & 68.0692 & 50.0000 & 34.9999 & 30.0000 & 40.0000 & 948.3052 & 0.205200 & 4.4839 & - \\
\hline SMA & 61.1709 & 67.6666 & 50.0000 & 35.0000 & 30.0000 & 40.0000 & 945.0454 & 0.204887 & 3.4375 & 60.11 \\
\hline
\end{tabular}

\subsubsection{Case 3: Transmission Loss Minimization}

Case 3 investigated the SMA performance by minimizing transmission line loss. Table 5 depicts the comparison results of the SMA with various algorithms in the literature comprising of PSO [18], MVO [18], GOA [18], HHO [18], SSA [19], WOA [19], MF [19], GSO [19], DE [21], GWO [21], and multi-objective harmony search (MOHS) [47].

Table 5. Comparison results of the SMA with other algorithms for case 3.

\begin{tabular}{|c|c|c|c|c|c|c|c|c|c|c|}
\hline Algorithms & $P_{g 1}(\mathrm{MW})$ & $P_{g^{2}}(\mathrm{MW})$ & $P_{g 5}(\mathrm{MW})$ & $P_{g 8}(\mathrm{MW})$ & $P_{g 11}(\mathrm{MW})$ & $P_{g 13}(\mathrm{MW})$ & Cost $(\$ / h)$ & $\begin{array}{c}\text { Emission } \\
\text { (ton/h) }\end{array}$ & Loss (MW) & Time (s) \\
\hline PSO [18] & - & 80.0000 & 50.0000 & 10.0000 & 10.0000 & 40.0000 & 931.2200 & - & 10.3822 & - \\
\hline MVO [18] & - & 25.8570 & 25.7890 & 21.2720 & 28.1110 & 12.9630 & 817.1171 & - & 9.7700 & - \\
\hline GOA [18] & - & 68.6191 & 50.0000 & 27.5100 & 17.0215 & 24.6921 & 878.8137 & - & 5.8100 & - \\
\hline HHO [18] & - & 43.1710 & 50.0000 & 29.9360 & 30.0000 & 28.8280 & 915.0934 & - & 4.5600 & - \\
\hline SSA [19] & 51.9000 & 80.0000 & 50.0000 & 35.0000 & 30.0000 & 40.0000 & 968.5600 & 0.296000 & 3.5000 & 61.00 \\
\hline WOA [19] & 52.0300 & 79.9600 & 49.9700 & 34.9800 & 29.9800 & 39.9800 & 968.2100 & 0.296000 & 3.5000 & 61.00 \\
\hline MF [19] & 51.9000 & 80.0000 & 50.0000 & 35.0000 & 30.0000 & 40.0000 & 968.5600 & 0.296000 & 3.5000 & 62.00 \\
\hline GSO [19] & 52.1000 & 80.0000 & 50.0000 & 34.8000 & 30.0000 & 40.0000 & 968.2900 & 0.297000 & 3.5100 & 65.00 \\
\hline $\mathrm{DE}[21]$ & 51.8200 & 79.9900 & 49.9900 & 35.0000 & 29.9800 & 40.0000 & 968.2300 & 0.207311 & 3.3800 & 16.50 \\
\hline GWO [21] & 51.8100 & 80.0000 & 50.0000 & 35.0000 & 30.0000 & 40.0000 & 968.3800 & 0.207310 & 3.4100 & 15.90 \\
\hline MOHS [47] & 66.2759 & 79.6413 & 46.8835 & 34.8880 & 29.1213 & 30.0558 & 928.5099 & 0.212890 & 3.5165 & - \\
\hline SMA & 51.6976 & 80.0000 & 50.0000 & 35.0000 & 30.0000 & 40.0000 & 968.1335 & 0.207294 & 3.2975 & 60.66 \\
\hline
\end{tabular}




\subsubsection{Case 4: Fuel Cost and Emission Minimizations}

For the MOOPF problem, fuel cost, and emission were simultaneously considered as part of the objective functions to be minimized in case 4 . The two-dimensional Pareto fronts provided by the SMA are compared with those of the high-performance well-known algorithm which is PSO obtained from [23] as presented in Figure 2.

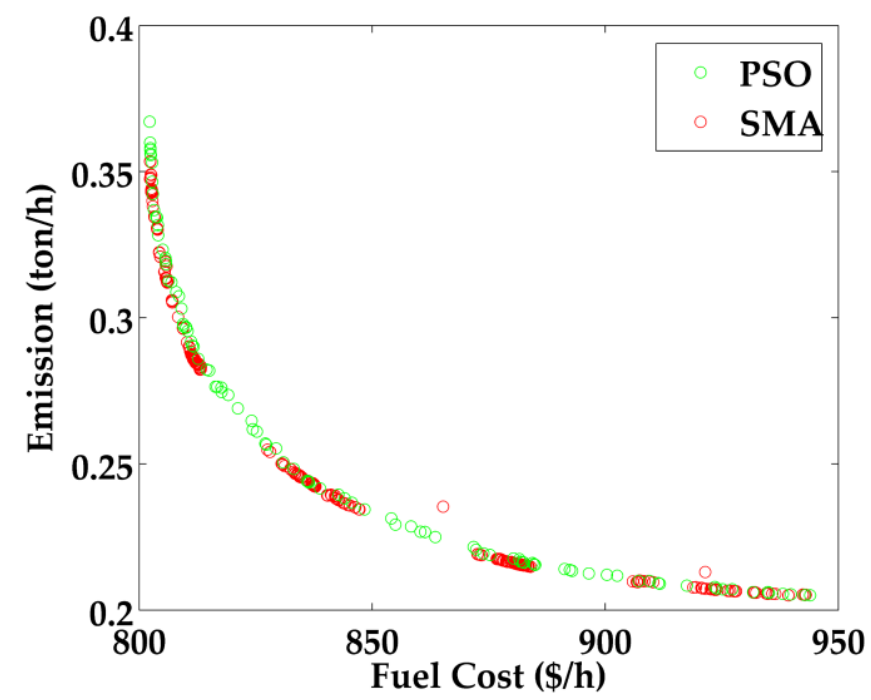

Figure 2. Two-dimensional Pareto fronts for case 4.

4.1.5. Case 5: Fuel Cost and Transmission Loss Minimizations

In case 5, the two objective functions selected for the MOOPF problem were fuel cost and transmission loss. Figure 3 shows the two-dimensional Pareto fronts obtained by the SMA when compared with those of the PSO.

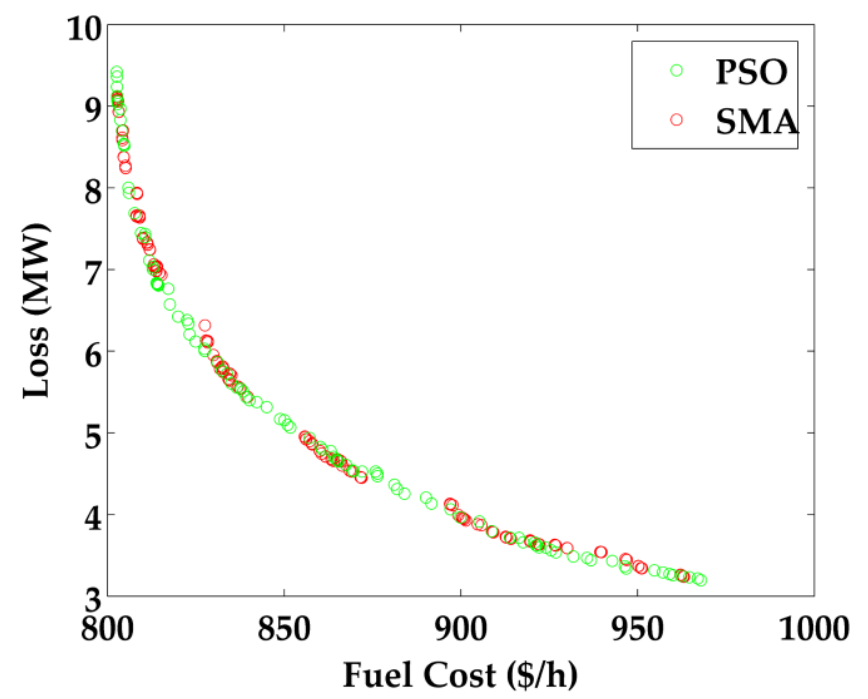

Figure 3. Two-dimensional Pareto fronts for case 5.

4.1.6. Case 6: Emission and Transmission Loss Minimizations

This case displays the MOOPF problem where emission and transmission loss were simultaneously chosen as part of the objective functions. The comparison of the Pareto fronts provided by the SMA and PSO are given in Figure 4. 


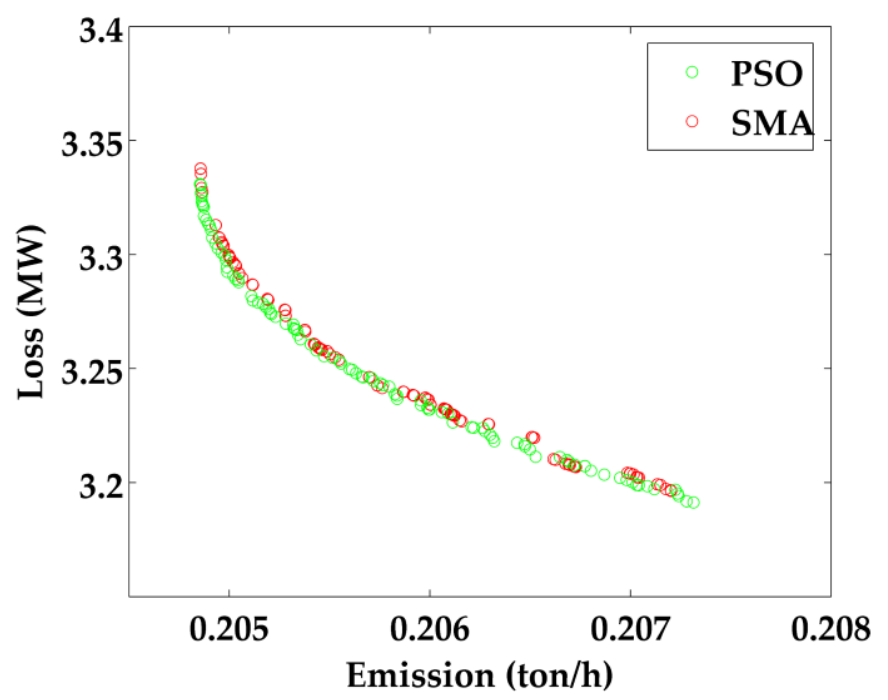

Figure 4. Two-dimensional Pareto fronts for case 6.

\subsubsection{Case 7: Fuel Cost, Emission, and Transmission Loss Minimizations}

For this case, all three objective functions including fuel cost, emission, and transmission loss were simultaneously considered as part of the objective functions in the MOOPF problem. The three-dimensional Pareto fronts generated by the SMA are shown in Figure 5.

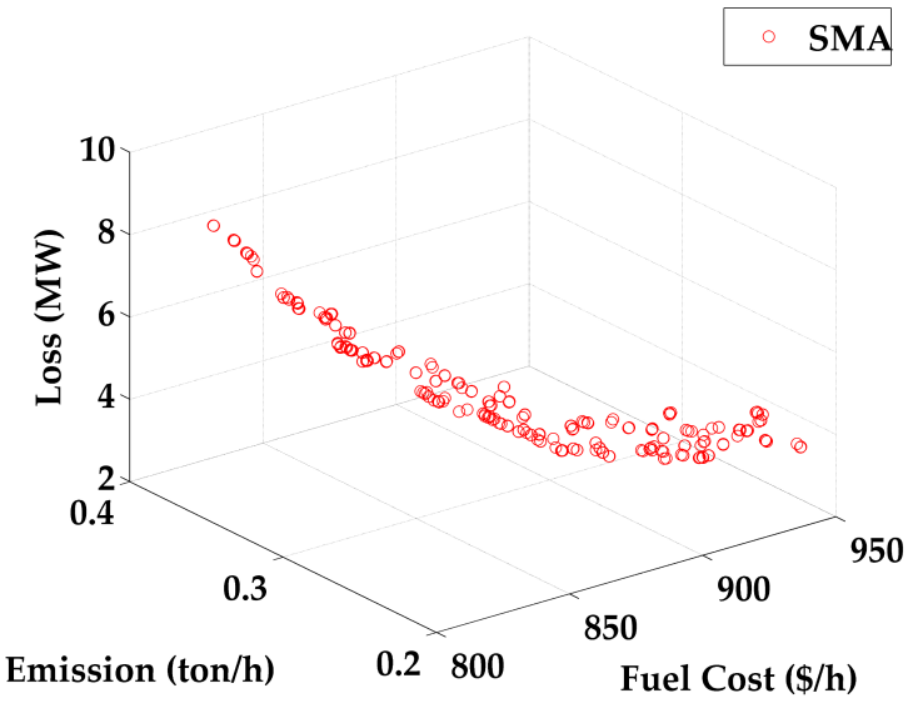

Figure 5. Three-dimensional Pareto fronts for case 7.

For the IEEE 30-bus system, when solving the single-objective function, it can be seen that the SMA could provide slightly better values of each objective than many competitive algorithms such as GWO, WOA, HHO, and SSA and well-known algorithms such as PSO and GA. The computational times of the SMA on solving each objective function are found to be slightly slower than some algorithms and also slightly faster than some algorithms. Besides, for the MOOPF problems, the SMA could efficiently produce the two dimensional Pareto fronts which are slightly better than those of the PSO for the pair of cost-emission objectives, competitive to those of the PSO for the pair of cost-loss objective, and slightly worse than those of the PSO for the pair of emission-loss objectives. The three-dimensional Pareto fronts could also be successfully generated with good diversity. It is worth mentioning that the system operators can judiciously select the fronts depending on the situation and aim. Thus, the SMA has a high performance in solving both singleand multi-objective OPF problems in the IEEE 30-bus system. 


\subsection{IEEE 57-Bus System}

The IEEE 57-bus system was used to verify the performance of the SMA on solving the OPF problems in a larger system. It comprised seven generators, 15 transformers, and 80 transmission lines. The total active power demand was $1250.8 \mathrm{MW}$, and the total reactive power demand was 336.4 MVAR. The bus data and branch data of the system were presented in [48]. The population number was 100, the maximum iteration was 200, and the Pareto repository was 100 . Single- and multi-objective OPF problems were solved in the IEEE 57-bus system as in cases 8-12.

For the IEEE 57-bus system, the single-objective OPF problem considering each objective function was solved by the SMA as in cases 8-10. The simulation results consisting of the control variables, active power at the slack bus, fuel cost, emission, and line loss of the SMA for each case are shown in Table 6.

Table 6. Simulation results of the SMA on solving single-objective OPF problem in the IEEE 57-bus system.

\begin{tabular}{|c|c|c|c|}
\hline Variables & Case 8 & Case 9 & Case 10 \\
\hline$P_{g 2}(\mathrm{MW})$ & 87.5816 & 100.0000 & 0.0002 \\
\hline$P_{g 3}(\mathrm{MW})$ & 45.0495 & 140.0000 & 139.08703 \\
\hline$P_{g 6}^{\circ}(\mathrm{MW})$ & 72.3423 & 100.0000 & 100.0000 \\
\hline$P_{g 8}(\mathrm{MW})$ & 461.4124 & 292.4454 & 309.0071 \\
\hline$P_{g 9}(\mathrm{MW})$ & 97.1093 & 100.0000 & 100.0000 \\
\hline$P_{g 12}(\mathrm{MW})$ & 360.3751 & 298.7228 & 410.0000 \\
\hline$V_{g 1}$ (p.u.) & 1.0500 & 1.0500 & 1.0500 \\
\hline$V_{g 2}$ (p.u.) & 1.0497 & 1.0513 & 0.9991 \\
\hline$V_{g 3}$ (p.u.) & 1.0491 & 1.0524 & 1.0040 \\
\hline$V_{g 6}$ (p.u.) & 1.0638 & 1.0476 & 1.0057 \\
\hline$V_{g 8}$ (p.u.) & 1.0847 & 1.0511 & 1.0104 \\
\hline$V_{g 9}$ (p.u.) & 1.0498 & 1.0260 & 0.9876 \\
\hline$V_{g 12}$ (p.u.) & 1.0446 & 1.0296 & 0.9927 \\
\hline$T_{4-8}$ (p.u.) & 1.0483 & 0.9474 & 1.0678 \\
\hline$T_{4-18}$ (p.u.) & 0.9158 & 0.9842 & 0.9000 \\
\hline$T_{21-20}$ (p.u.) & 1.0147 & 1.0188 & 1.0100 \\
\hline$T_{24-25}$ (p.u.) & 0.9130 & 0.9000 & 0.9768 \\
\hline$T_{24-25}$ (p.u.) & 0.9265 & 0.9132 & 1.0452 \\
\hline$T_{24-26}$ (p.u.) & 1.0253 & 1.0024 & 1.0058 \\
\hline$T_{7-29}$ (p.u.) & 0.9910 & 0.9755 & 0.9504 \\
\hline$T_{34-32}$ (p.u.) & 0.9272 & 0.9076 & 0.9551 \\
\hline$T_{11-41}$ (p.u.) & 0.9060 & 0.9000 & 0.9000 \\
\hline$T_{15-45}$ (p.u.) & 0.9713 & 0.9735 & 0.9334 \\
\hline$T_{14-46}$ (p.u.) & 0.9616 & 0.9599 & 0.9237 \\
\hline$T_{10-51}$ (p.u.) & 0.9779 & 0.9740 & 0.9285 \\
\hline$T_{13-49}$ (p.u.) & 0.9319 & 0.9280 & 0.9000 \\
\hline$T_{11-43}$ (p.u.) & 0.9779 & 0.9612 & 0.9200 \\
\hline$T_{40-56}$ (p.u.) & 1.0030 & 0.9872 & 0.9986 \\
\hline$T_{39-57}$ (p.u.) & 0.9714 & 0.9499 & 0.9672 \\
\hline$T_{9-55}$ (p.u.) & 0.9913 & 0.9719 & 0.9393 \\
\hline$Q c_{18}$ (MVar) & 17.1616 & 18.9562 & 16.3642 \\
\hline$Q c_{25}$ (MVar) & 12.9818 & 2.2834 & 14.8678 \\
\hline$Q_{c_{53}}$ (MVar) & 21.6527 & 14.3542 & 13.6294 \\
\hline$P_{g 1}(\mathrm{MW})$ & 147.4855 & 236.4739 & 202.5958 \\
\hline Fuel Cost $(\$ / h)$ & $41,697.1189$ & $45,670.1789$ & $45,049.1328$ \\
\hline Emission (ton $/ \mathrm{h}$ ) & 1.9332 & 1.0813 & 1.4032 \\
\hline Loss (MW) & 15.5557 & 16.8421 & 10.6734 \\
\hline
\end{tabular}

\subsubsection{Case 8: Fuel Cost Minimization}

The fuel cost was chosen as the objective function in this case. The fuel cost result obtained by the SMA is compared with those of various other algorithms in the literature such as PSO [23], dragonfly algorithm (DA) [23], GBICA [26], MGBICA [26], evolving 
ant direction differential evolution (EADDE) [49], Fuzzy-GA [50], particle swarm optimization with linearly decreasing inertia weight (LDI-PSO) [51], adaptive particle swarm optimization (APSO) [52], and new particle swarm optimization (NPSO) [53] as expressed in Table 7.

Table 7. Comparison results of the SMA with other algorithms for case 8 .

\begin{tabular}{cc}
\hline Algorithms & Cost $\mathbf{( \$ / h )}$ \\
\hline PSO [23] & $41,698.3672$ \\
DA [23] & $41,828.4473$ \\
GBICA [26] & $41,740.2884$ \\
MGBICA [26] & $41,715.7101$ \\
EADDE [49] & $41,713.6200$ \\
Fuzzy-GA [50] & $41,716.2808$ \\
LDI-PSO [51] & $41,815.5035$ \\
APSO [52] & $41,713.8868$ \\
NPSO [53] & $41,699.5163$ \\
SMA & $\mathbf{4 1 , 6 9 7 . 1 1 8 9}$ \\
\hline
\end{tabular}

\subsubsection{Case 9: Emission Minimization}

In this case, the performance of the SMA was evaluated for solving the OPF problem when emission was considered to be minimized. The emission comparison results of the SMA with those of PSO [23], DA [23], GBICA [26], and MGBICA [26] are given in Table 8.

Table 8. Comparison results of the SMA with other algorithms for case 9.

\begin{tabular}{cc}
\hline Algorithms & Emission $\mathbf{( \$ / h )}$ \\
\hline PSO [23] & 1.0814 \\
DA [23] & 1.3097 \\
GBICA [26] & 1.1881 \\
MGBICA [26] & 1.1724 \\
SMA & $\mathbf{1 . 0 8 1 3}$ \\
\hline
\end{tabular}

\subsubsection{Case 10: Transmission Loss Minimization}

This case simulated the OPF problem when transmission loss was an objective function. Table 9 shows the comparison results provided by the SMA with those of PSO [23] and DA [23].

Table 9. Comparison results of the SMA with other algorithms for case 10.

\begin{tabular}{cc}
\hline Algorithms & Loss $\mathbf{( \$ / h )}$ \\
\hline PSO [23] & 10.7076 \\
DA [23] & 13.6430 \\
SMA & $\mathbf{1 0 . 6 7 3 4}$ \\
\hline
\end{tabular}

\subsubsection{Case 11: Fuel Cost and Emission Minimizations}

In this case, the MOOPF problem was investigated in the IEEE 57-bus system where fuel cost and emission were simultaneously considered as part of the objective functions. The two-dimensional Pareto fronts generated by the SMA are presented in Figure 6 when compared with those of PSO obtained from [23]. 


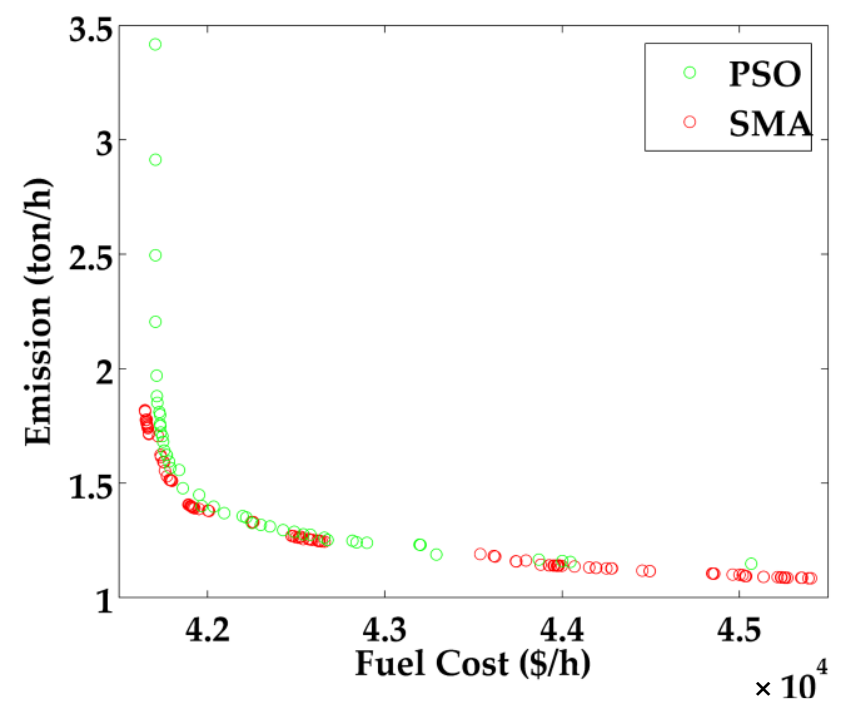

Figure 6. Two-dimensional Pareto fronts for case 11.

4.2.5. Case 12: Fuel Cost, Emission, and Transmission Loss Minimizations

The fuel cost, emission, and transmission loss were simultaneously minimized for the MOOPF problem in this case. The three-dimensional Pareto fronts provided by the SMA is displayed in Figure 7.

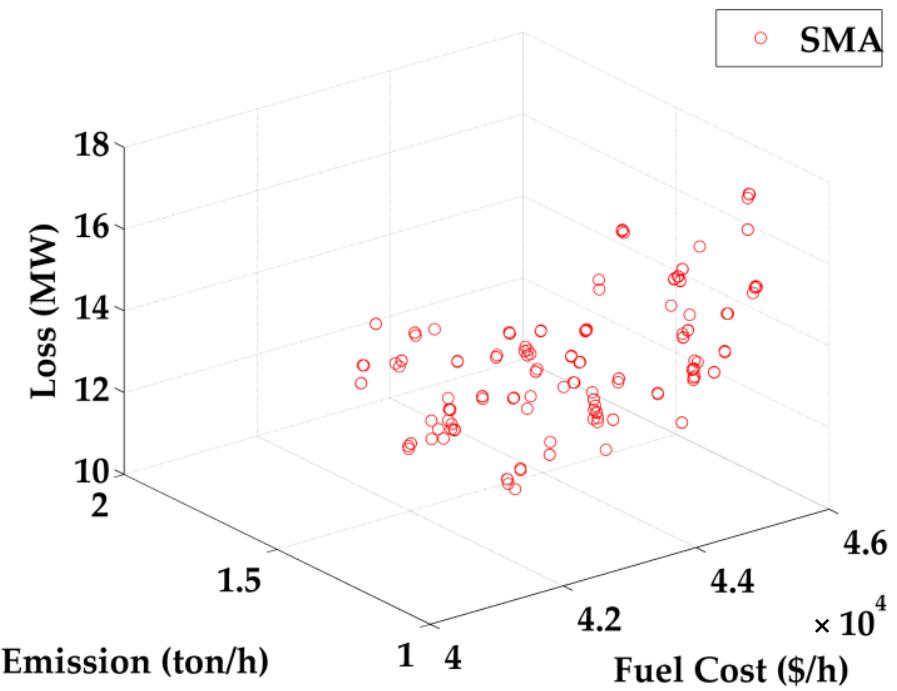

Figure 7. Three-dimensional Pareto fronts for case 12.

In the larger system, which is the IEEE 57-bus system, the simulation results for each single-objective function provided by the SMA are found to be significantly better than those of many other algorithms in the literature. Moreover, the two-dimensional Pareto fronts generated by the SMA are significantly better than those of the PSO as evident in Figure 6, and the three-dimensional Pareto fronts could also be efficiently obtained with good diversity as in Figure 7. Hence, the SMA also has superiority over various other algorithms for the IEEE 57-bus system. 


\subsection{IEEE 118-Bus System}

To verify the performance of the SMA in a large system, the MOOPF problem was solved in the IEEE 118-bus system. This system includes 54 generators, nine transformers, and 186 transmission lines. The active power demand was $4242 \mathrm{MW}$, and the reactive power demand was 1439 MVAR. The line diagram of this system, bus data, and branch data are presented in [54]. In the simulation, the population number and the maximum iteration were 100 and 500, respectively. The objective function was the fuel cost as in case 13 for the OPF problem, and the fuel cost and transmission loss were the objective functions for the MOOPF problem as in case 14 .

The simulation results including control variables, active power generation at the slack bus $\left(P_{g 69}\right)$, fuel cost, and transmission loss provided by the SMA when considering fuel cost as the objective function for this system are depicted in Table 10.

Table 10. Simulation results of the SMA on solving single-objective OPF problem in the IEEE 118-bus system (case 13).

\begin{tabular}{|c|c|c|c|c|c|c|c|c|c|}
\hline Variables & Value & Variables & Value & Variables & Value & Variables & Value & Variables & Value \\
\hline$P_{g 1}$ & 24.2893 & $P_{g 65}$ & 350.0392 & $V_{g 1}$ & 1.0124 & $V_{g 65}$ & 1.0734 & $T_{8-5}$ & 1.0145 \\
\hline$P_{g 4}^{\circ}$ & 0.0009 & $P_{g 66}^{0}$ & 347.3154 & $V_{g 4}$ & 1.0406 & $V_{g 66}$ & 1.0726 & $T_{26-25}$ & 1.0596 \\
\hline$P_{g 6}^{0}$ & 0.0739 & $P_{g 69}$ & 450.8800 & $V_{g 6}^{0}$ & 1.0307 & $V_{g 69}^{0}$ & 1.0500 & $T_{30-17}$ & 1.0048 \\
\hline$P_{g 8}^{0}$ & 0.0017 & $P_{g 70}$ & 0.0000 & $V_{g 8}$ & 1.0631 & $V_{g 70}$ & 1.0302 & $T_{38-37}$ & 1.0028 \\
\hline$P_{g 10}^{\circ}$ & 401.1827 & $P_{g 72}$ & 0.0336 & $V_{g 10}^{o}$ & 1.0809 & $V_{g 72}$ & 1.0405 & $T_{63-59}$ & 0.9976 \\
\hline$P_{g 12}$ & 85.2703 & $P_{g 73}$ & 0.0020 & $V_{g 12}^{\delta}$ & 1.0279 & $V_{g 73}$ & 1.0323 & $T_{64-61}$ & 1.0014 \\
\hline$P_{g 15}$ & 17.7886 & $P_{g 74}$ & 30.7956 & $V_{g 15}$ & 1.0306 & $V_{g 74}^{0}$ & 1.0046 & $T_{65-66}$ & 0.9846 \\
\hline$P_{g 18}$ & 10.2734 & $P_{g 76}$ & 15.8494 & $V_{g 18}^{\delta}$ & 1.0336 & $V_{g 76}^{\delta}$ & 0.9908 & $T_{68-69}$ & 0.9613 \\
\hline$P_{g 19}$ & 19.1983 & $P_{g 77}$ & 0.0000 & $V_{g 19}^{\delta}$ & 1.0306 & $V_{g 77}$ & 1.0244 & $T_{81-80}$ & 1.0065 \\
\hline$P_{g 24}$ & 0.0060 & $P_{g 80}$ & 425.6445 & $V_{g 24}$ & 1.0557 & $V_{g 80}$ & 1.0390 & $Q_{c 5}$ & 13.2283 \\
\hline$P_{g 25}$ & 195.6545 & $P_{g 85}$ & 0.0007 & $V_{g 25}$ & 1.0841 & $V_{g 85}$ & 1.0351 & $\tilde{Q}_{c 34}$ & 11.3758 \\
\hline$P_{g 26}$ & 280.7702 & $P_{g 87}$ & 3.5654 & $V_{g 26}$ & 1.100 & $V_{g 87}$ & 1.0316 & $Q_{c 37}$ & 9.7585 \\
\hline$P_{g 27}$ & 9.9981 & $P_{g 89}$ & 491.5026 & $V_{g 27}$ & 1.0455 & $V_{g 89}$ & 1.0601 & $Q_{c 44}$ & 19.2924 \\
\hline$P_{g 31}^{\circ}$ & 7.2554 & $P_{g 90}^{\circ}$ & 0.0000 & $V_{g 31}$ & 1.0352 & $V_{g 90}^{0}$ & 1.0375 & $Q_{c 45}$ & 13.1391 \\
\hline$P_{g 32}^{801}$ & 14.7818 & $P_{g 91}$ & 0.0000 & $V_{g 32}^{801}$ & 1.0419 & $V_{g 91}^{\delta}$ & 1.0370 & $\widetilde{Q}_{c 46}$ & 5.3581 \\
\hline$P_{g 34}^{\circ}$ & 0.1505 & $P_{g 92}^{0}$ & 0.0000 & $V_{g 34}^{\circ}$ & 1.0326 & $V_{g 92}^{0}$ & 1.0415 & $Q_{c 48}$ & 17.9075 \\
\hline$P_{g 36}^{\circ}$ & 6.2819 & $P_{g 99}^{0}$ & 0.0000 & $V_{g 36}^{0}$ & 1.0286 & $V_{g 99}^{\delta}$ & 1.0331 & $\widetilde{Q}_{c 74}$ & 17.6414 \\
\hline$P_{g 40}$ & 47.7139 & $P_{g 100}$ & 222.2925 & $V_{g 40}$ & 1.0225 & $V_{g 100}$ & 1.0371 & $Q_{c 79}$ & 17.8135 \\
\hline$P_{g 42}^{0}$ & 39.3872 & $P_{g 103}^{0}$ & 140.0000 & $V_{g 42}$ & 1.0270 & $V_{g 103}$ & 1.0330 & $\widetilde{Q}_{c 82}$ & 14.6916 \\
\hline$P_{g 46}$ & 18.9393 & $P_{g 104}$ & 0.0069 & $V_{g 46}$ & 1.0397 & $V_{g 104}$ & 1.0132 & $Q_{c 83}$ & 17.5557 \\
\hline$P_{g 49}$ & 192.7297 & $P_{g 105}$ & 0.0002 & $V_{g 49}^{\delta}$ & 1.0542 & $V_{g 105}^{\delta}$ & 1.0081 & $\widetilde{Q}_{c 105}$ & 2.0871 \\
\hline$P_{g 54}$ & 49.1554 & $P_{g 107}$ & 12.8200 & $V_{g 54}$ & 1.0314 & $V_{g 107}^{\circ}$ & 0.9969 & $Q_{c 107}$ & 24.0126 \\
\hline$P_{g 55}^{\circ}$ & 28.9861 & $P_{g 110}$ & 0.0000 & $V_{g 55}^{0}$ & 1.0307 & $V_{g 110}$ & 1.0055 & $\widetilde{Q}_{c 110}$ & 19.5937 \\
\hline$P_{g 56}$ & 29.6747 & $P_{g 111}$ & 34.1021 & $V_{g 56}$ & 1.0311 & $V_{g 111}$ & 1.0134 & Cost $(\$ / h)$ & $127,896.5465$ \\
\hline$P_{g 59}$ & 148.4311 & $P_{g 112}$ & 21.1173 & $V_{g 59}$ & 1.0532 & $V_{g 112}$ & 0.9941 & & \\
\hline$P_{g 61}$ & 147.4476 & $P_{g 113}$ & 0.0000 & $V_{g 61}^{\delta}$ & 1.0617 & $V_{g 113}$ & 1.0422 & n (ton/h) & 8.4962 \\
\hline$P_{g 62}$ & 0.0020 & $P_{g 116}$ & 0.0001 & $V_{g 62}^{0}$ & 1.0589 & $V_{g 116}$ & 1.0680 & Loss (MW) & 79.4121 \\
\hline
\end{tabular}

\subsubsection{Case 13: Fuel Cost Minimization}

This case selected the fuel cost as the objective function to be minimized. The fuel cost value provided by the SMA is compared with several algorithms including GWO [21], DE [21], DSA [55], TLBO [55], harmony search algorithm (HSA) [56], fuzzy harmony search algorithm (FHSA) [56], gravitational search algorithm (GSA) [57], hybrid PSO and GSA (PSOGSA) [58], improved colliding bodies optimization (ICBO) [59], moth swarm algorithm (MSA) [60], sine-cosine algorithm (SCA) [61], and modified SCA (MSCA) [61] as shown in Table 11. 
Table 11. Comparison results of the SMA with other algorithms for case 13.

\begin{tabular}{cc}
\hline Algorithms & Cost $\mathbf{( \$ / h )}$ \\
\hline GWO [21] & $129,720.0000$ \\
DE [21] & $129,582.0000$ \\
DSA [55] & $129,691.6152$ \\
TLBO [55] & $129,682.8440$ \\
HSA [56] & $132,319.6000$ \\
FHSA [56] & $132,138.3000$ \\
GSA [57] & $129,565.0000$ \\
PSOGSA [58] & $129,733.5800$ \\
ICBO [59] & $135,121.5704$ \\
MSA [60] & $129,640.7191$ \\
SCA [61] & $129,622.6500$ \\
MSCA [61] & $129,620.2200$ \\
SMA & $\mathbf{1 2 7 , 8 9 6 . 5 4 6 5}$ \\
\hline
\end{tabular}

\subsubsection{Case 14: Fuel Cost and Loss Minimizations}

For the IEEE 118-bus system, fuel cost and line loss were simultaneously chosen as the objective functions for the MOOPF in this case. The two-dimensional Pareto fronts generated by the SMA are presented in Figure 8.

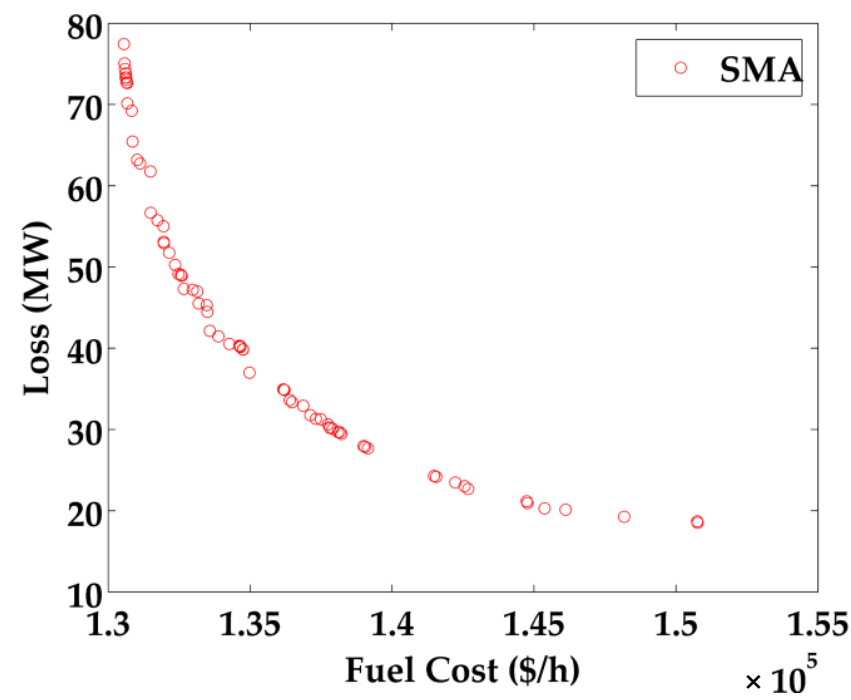

Figure 8. Two-dimensional Pareto fronts for case 14.

From the simulation results in the IEEE 118-bus system, which is the largest system in this study, it is found that the SMA could efficiently solve the single-objective OPF problem and provide considerably better fuel cost value than many other algorithms in the literature as evident in Table 11. Moreover, for solving the MOOPF problem, two-dimensional Pareto fronts were successfully generated as evident in Figure 8 where the PSO could not converge to the solutions within the defined iterations.

Thus, it is found from all simulation results that the SMA has a high performance on solving the OPF problems including both single- and multi-objective OPF problems. The obtained results for all considered objectives are better than those of several other algorithms in the literature for all test systems where SMA could successfully provide high-quality solutions in the large systems. The computational times of the SMA are also competitive to those of other algorithms. For the MOOPF problems, even though the considered objective functions including fuel cost, emission, and transmission loss conflict with each other, the SMA could provide the solutions which is a trade-off between each objective because of its high-quality random search property. The SMA could efficiently provide two- and three-dimensional Pareto fronts with good diversity in all test systems 
where the Pareto fronts are better than those of the PSO, which is an effective well-known algorithm. This is because the SMA has the process of producing positive and negative feedbacks of propagation wave to well balance the exploration and exploitation phases of the optimization process.

In practical systems, the system operators can judiciously choose the suitable solution from the generated Pareto fronts by considering the situation and objective in order to achieve the high profit for the power generation or satisfy the power generation situation. For example, when the high demand is required, the operators should select the least transmission loss solution, so that the power generation is adequate for the required high demand. When the pollution situation deteriorates, the emission objective should be minimized to alleviate the situation. However, in the normal situation, the cost can be the best objective function to be minimized, so the power companies can dispatch the generation with the highest profit. It can be noticed from the simulation results that the SMA can sharply increase the profit for the power companies especially when the system is large. For example, in the IEEE 118-bus system, when fuel cost is considered as the objective function, the SMA can reduce the cost around 1685.4535 to $7225.0239 \$ / \mathrm{h}$ or $40,450.8840$ to $173,400.5736$ \$/day compared to other algorithms.

\section{Conclusions}

This paper presents a method to solve MOOPF problems based on SMA by considering fuel cost, emission, and transmission line loss as part of the objective functions to be minimized. The SMA is a recently proposed algorithm, which has been applied to successfully solve many optimization problems in several fields. However, the SMA has been rarely investigated on solving the single-objective OPF problem and never been evaluated on solving the MOOPF problem. So, this work has introduced a method to solve the MOOPF problems based on SMA and investigated the performance of the SMA on solving both single-objective and multi-objective OPF problems. The IEEE 30-, 57-, and 118-bus systems were employed to evaluate the performance of the SMA. The simulation results show that the SMA could successfully solve the single-objective OPF problem. The SMA provided slightly better solutions for the IEEE 30-bus system, moderately better solutions for the IEEE 57-bus system, and significantly better solutions for the IEEE 118-bus system in terms of the objective values than many other algorithms in the literature. For the MOOPF problems, the two-dimensional Pareto fronts generated by the SMA are better than those of the well-known high-performance algorithm which is the PSO algorithm. Especially in the IEEE 118-bus system, the SMA could efficiently obtain the Pareto fronts while PSO could not converge to the solutions within the imposed iteration. Moreover, the three-dimensional Pareto fronts could also be efficiently provided by the SMA where the operators should judiciously choose the appropriate solution depending on the objective and situation. Hence, the SMA is verified as a high-performance algorithm for solving both single-objective and multi-objective OPF problems, especially in large systems. In future work, the SMA can be applied to solve the OPF problems in practical systems where the system sizes are generally large, and many-objective OPF problems (more than three objective functions) can be solved based on SMA to further improve power system performance in several terms.

Author Contributions: Conceptualization, S.K.; methodology, S.K.; software, S.K.; validation, S.K., A.S. and S.P.; formal analysis, S.K.; investigation, S.K.; resources, S.K.; data curation, S.K.; writingoriginal draft preparation, S.K.; writing-review and editing, S.K., A.S. and S.P.; visualization, S.K.; supervision, S.K., A.S. and S.P.; project administration, S.K. and A.S.; funding acquisition. All authors have read and agreed to the published version of the manuscript.

Funding: This research received no external funding.

Institutional Review Board Statement: Not applicable.

Informed Consent Statement: Not applicable. 
Data Availability Statement: No new data were created or analyzed in this study. Data sharing is not applicable to this article.

Conflicts of Interest: The authors declare no conflict of interest.

\section{References}

1. Biswas, P.P.; Suganthan, P.N.; Amaratunga, G.A.J. Optimal power flow solutions incorporating stochastic wind and solar power. Energy Convers. Manag. 2017, 148, 1194-1207. [CrossRef]

2. Mohagheghi, E.; Gabash, A.; Alramlawi, M.; Li, P. Real-time optimal power flow with reactive power dispatch of wind stations using a reconciliation algorithm. Renew. Energy 2018, 126, 509-523. [CrossRef]

3. Luo, J.; Shi, L.; Ni, Y. A solution of optimal power flow incorporating wind generation and power grid uncertainties. IEEE Access 2018, 6, 19681-19690. [CrossRef]

4. Ma, H.; Hart, J.L. Economic Dispatch in View of the Clean Air Act of 1990. IEEE Trans. Power Syst. 2000, 9, 972-978.

5. Roy, P.K.; Ghoshal, S.P.; Thakur, S.S. Biogeography based optimization for multi-constraint optimal power flow with emission and non-smooth cost function. Expert Syst. Appl. 2010, 37, 8221-8228. [CrossRef]

6. Burchett, R.C.; Happ, H.H.; Vierath, D.R. Quadratically Convergent Optimal Power Flow. IEEE Trans. Power Appar. Syst. 1984, PAS-103, 3267-3275. [CrossRef]

7. Yan, X.; Quintana, V.H. Improving an interior-point-based off by dynamic adjustments of step sizes and tolerances. IEEE Trans. Power Syst. 1999, 14, 709-716. [CrossRef]

8. Momoh, J.A.; El-Hawary, M.E.; Adapa, R. A review of selected optimal power flow literature to 1993 part I: Nonlinear and quadratic Programming Approaches. IEEE Trans. Power Syst. 1999, 14, 96-103. [CrossRef]

9. Yodphet, D.; Onlam, A.; Siritaratiwat, A.; Khunkitti, P. Electrical distribution system reconfiguration for power loss reduction by the Salp Swarm algorithm. Int. J. Smart Grid Clean Energy 2019, 8, 156-163. [CrossRef]

10. Chamchuen, S.; Siritaratiwat, A.; Fuangfoo, P.; Suthisopapan, P.; Khunkitti, P. High-Accuracy Power Quality Disturbance Classification Using the Adaptive ABC-PSO As Optimal Feature Selection Algorithm. Energies 2021, 14, 1238. [CrossRef]

11. Khaboot, N.; Srithapon, C.; Siritaratiwat, A.; Khunkitti, P. Increasing Benefits in High PV Penetration Distribution System by Using Battery Enegy Storage and Capacitor Placement Based on Salp Swarm Algorithm. Energies 2019, 12, 4817. [CrossRef]

12. Nuaekaew, K.; Artrit, P.; Pholdee, N.; Bureerat, S. Optimal reactive power dispatch problem using a two-archive multi-objective grey wolf optimizer. Expert Syst. Appl. 2017, 87, 79-89. [CrossRef]

13. Khunkitti, S.; Premrudeepreechacharn, S.; Siritaratiwat, A.; Watson, N.R. Power system voltage stability enhancement based on line voltage stability indices in heavily loaded and line outage contingency situations. Int. J. Eng. Res. Technol. 2020, 13, 1635-1648. [CrossRef]

14. Khunkitti, S.; Premrudeepreechacharn, S.; Chatthaworn, R.; Thasnas, N.; Khunkitti, P.; Siritaratiwat, A.; Watson, N.R. A comparison of the effectiveness of voltage stability indices in an optimal power flow. IEEJ Trans. Electr. Electron. Eng. 2019, 14, 534-544. [CrossRef]

15. Khunkitti, S.; Watson, N.; Chatthaworn, R.; Premrudeepreechacharn, S.; Siritaratiwat, A. An Improved DA-PSO Optimization Approach for Unit Commitment Problem. Energies 2019, 12, 2335. [CrossRef]

16. Boonluk, P.; Siritaratiwat, A.; Fuangfoo, P.; Khunkitti, S. Optimal siting and sizing of battery energy storage systems for distribution network of distribution system operators. Batteries 2020, 6, 56. [CrossRef]

17. Boonluk, P.; Khunkitti, S.; Fuangfoo, P.; Siritaratiwat, A. Optimal Siting and Sizing of Battery Energy Storage: Case Study Seventh Feeder at Nakhon Phanom Substation in Thailand. Energies 2021, 14, 1458. [CrossRef]

18. Diab, H.; Abdelsalam, M.; Abdelbary, A. A Multi-Objective Optimal Power Flow Control of Electrical Transmission Networks Using Intelligent Meta-Heuristic Optimization Techniques. Sustainability 2021, 13, 4979. [CrossRef]

19. Islam, M.Z.; Wahab, N.I.A.; Veerasamy, V.; Hizam, H.; Mailah, N.F.; Guerrero, J.M.; Mohd Nasir, M.N. A Harris Hawks optimization based singleand multi-objective optimal power flow considering environmental emission. Sustainability 2020, 12, 5248. [CrossRef]

20. Sliman, L.; Bouktir, T. Economic Power Dispatch of Power System with Pollution Control using Multiobjective Ant Colony Optimization. Int. J. Comput. Intell. Res. 2007, 3, 145-153. [CrossRef]

21. El-Fergany, A.A.; Hasanien, H.M. Single and Multi-objective Optimal Power Flow Using Grey Wolf Optimizer and Differential Evolution Algorithms. Electr. Power Compon. Syst. 2015, 43, 1548-1559. [CrossRef]

22. Shang, R.; Wang, Y.; Wang, J.; Jiao, L.; Wang, S.; Qi, L. A multi-population cooperative coevolutionary algorithm for multi-objective capacitated arc routing problem. Inf. Sci. 2014, 277, 609-642. [CrossRef]

23. Khunkitti, S.; Siritaratiwat, A.; Premrudeepreechacharn, S.; Chatthaworn, R.; Watson, N. A Hybrid DA-PSO Optimization Algorithm for Multiobjective Optimal Power Flow Problems. Energies 2018, 11, 2270. [CrossRef]

24. Ghasemi, M.; Ghavidel, S.; Ghanbarian, M.M.; Gitizadeh, M. Multi-objective optimal electric power planning in the power system using Gaussian bare-bones imperialist competitive algorithm. Inf. Sci. 2015, 294, 286-304. [CrossRef]

25. Shabanpour-Haghighi, A.; Seifi, A.; Niknam, T. A modified teaching-learning based optimization for multi-objective optimal power flow problem. Energy Convers. Manag. 2014, 77, 597-607. [CrossRef]

26. Niknam, T.; Narimani, M.R.; Jabbari, M.; Malekpour, A.R. A modified shuffle frog leaping algorithm for multi-objective optimal power flow. Energy 2011, 36, 6420-6432. [CrossRef] 
27. Žilinskas, A.; Žilinskas, J. Adaptation of a one-step worst-case optimal univariate algorithm of bi-objective Lipschitz optimization to multidimensional problems. Commun. Nonlinear Sci. Numer. Simul. 2015, 21, 89-98. [CrossRef]

28. Žilinskas, A.; Fraga, E.S.; Mackute, A. Data analysis and visualisation for robust multi-criteria process optimisation. Comput. Chem. Eng. 2006, 30, 1061-1071. [CrossRef]

29. Nagar, D.; Ramu, P.; Deb, K. Interpretable Self-Organizing Maps (iSOM) for Visualization of Pareto Front in Multiple Objective Optimization. In Proceedings of the Evolutionary Multi-Criterion Optimization, 11th International Conference, EMO 2021, Shenzhen, China, 28-31 March 2021; pp. 645-655.

30. Mirjalili, S.; Mirjalili, S.M.; Lewis, A. Grey Wolf Optimizer. Adv. Eng. Softw. 2014, 69, 46-61. [CrossRef]

31. Mirjalili, S.; Lewis, A. The Whale Optimization Algorithm. Adv. Eng. Softw. 2016, 95, 51-67. [CrossRef]

32. Mirjalili, S.; Gandomi, A.H.; Mirjalili, S.Z.; Saremi, S.; Faris, H.; Mirjalili, S.M. Salp Swarm Algorithm: A bio-inspired optimizer for engineering design problems. Adv. Eng. Softw. 2017, 114, 163-191. [CrossRef]

33. Heidari, A.A.; Mirjalili, S.; Faris, H.; Aljarah, I.; Mafarja, M.; Chen, H. Harris hawks optimization: Algorithm and applications. Futur. Gener. Comput. Syst. 2019, 97, 849-872. [CrossRef]

34. Li, S.; Chen, H.; Wang, M.; Heidari, A.A.; Mirjalili, S. Slime mould algorithm: A new method for stochastic optimization. Futur. Gener. Comput. Syst. 2020, 111, 300-323. [CrossRef]

35. Kumar, C.; Raj, T.D.; Premkumar, M.; Raj, T.D. A new stochastic slime mould optimization algorithm for the estimation of solar photovoltaic cell parameters. Optik 2020, 223, 165277. [CrossRef]

36. Liu, M.; Li, Y.; Huo, Q.; Li, A.; Zhu, M.; Qu, N.; Chen, L.; Xia, M. A two-way parallel slime mold algorithm by flow and distance for the travelling salesman problem. Appl. Sci. 2020, 10, 6180. [CrossRef]

37. Zubaidi, S.L.; Abdulkareem, I.H.; Hashim, K.S.; Al-Bugharbee, H.; Ridha, H.M.; Gharghan, S.K.; Al-Qaim, F.F.; Muradov, M.; Kot, P.; Al-Khaddar, R. Hybridised artificial neural network model with slime mould algorithm: A novel methodology for prediction of urban stochastic water demand. Water 2020, 12, 2692. [CrossRef]

38. Kouadri, R.; Musirin, I.; Slimani, L.; Bouktir, T.; Othman, M.M. Optimal power flow control variables using slime mould algorithm for generator fuel cost and loss minimization with voltage profile enhancement solution. Int. J. Emerg. Trends Eng. Res. 2020, 8, 36-44. [CrossRef]

39. Niknam, T.; Narimani, M.R.; Aghaei, J.; Azizipanah-Abarghooee, R. Improved particle swarm optimisation for multi-objective optimal power flow considering the cost, loss, emission and voltage stability index. IET Gener. Transm. Distrib. 2012, 6, 515. [CrossRef]

40. Mirjalili, S.; Saremi, S.; Mirjalili, S.M.; Coelho, L.D.S. Multi-objective grey wolf optimizer: A novel algorithm for multi-criterion optimization. Expert Syst. Appl. 2016, 47, 106-119. [CrossRef]

41. The University of Washington Electrical Engineering. The University of Washington Electrical Engineering. Power System Test Case Archive, the IEEE 30-Bus Test System Data. Available online: https://www2.ee.washington.edu/research/pstca/pf30/pg tca30bus.htm (accessed on 19 April 2021).

42. Yuryevich, J.; Wong, K.P. Evolutionary Programming Based Optimal Power Flow Algorithm. IEEE Trans. Power Syst. 1999, 14, 1245-1250. [CrossRef]

43. Bouktir, T.; Slimani, L.; Mahdad, B. Optimal Power Dispatch for Large Scale Power System Using Stochastic Search Algorithms. Int. J. Power Energy Syst. 2008, 28. [CrossRef]

44. Sood, Y. Evolutionary programming based optimal power flow and its validation for deregulated power system analysis. Int. J. Electr. Power Energy Syst. 2007, 29, 65-75. [CrossRef]

45. Abaci, K.; Yamacli, V. Differential search algorithm for solving multi-objective optimal power flow problem. Int. J. Electr. Power Energy Syst. 2016, 79, 1-10. [CrossRef]

46. Narimani, M.R.; Azizipanah-Abarghooee, R.; Zoghdar-Moghadam-Shahrekohne, B.; Gholami, K. A novel approach to multiobjective optimal power flow by a new hybrid optimization algorithm considering generator constraints and multi-fuel type. Energy 2013, 49, 119-136. [CrossRef]

47. Sivasubramani, S.; Swarup, K.S. Multi-objective harmony search algorithm for optimal power flow problem. Int. J. Electr. Power Energy Syst. 2011, 33, 745-752. [CrossRef]

48. The University of Washington Electrical Engineering. The University of Washington Electrical Engineering. Power System Test Case Archive, the IEEE 57-Bus Test System Data. Available online: https://www2.ee.washington.edu/research/pstca/pf57/pg tca57bus.htm (accessed on 19 April 2021).

49. Vaisakh, K.; Srinivas, L.R. Evolving ant direction differential evolution for OPF with non-smooth cost functions. Eng. Appl. Artif. Intell. 2011, 24, 426-436. [CrossRef]

50. Hsiao, Y.T.; Chen, C.H.; Chien, C.C. Optimal capacitor placement in distribution systems using a combination fuzzy-GA method. Int. J. Electr. Power Energy Syst. 2004, 26, 501-508. [CrossRef]

51. Rezaei Adaryani, M.; Karami, A. Artificial bee colony algorithm for solving multi-objective optimal power flow problem. Int. J. Electr. Power Energy Syst. 2013, 53, 219-230. [CrossRef]

52. Mahdad, B.; Srairi, K. Hierarchical adaptive PSO for multi-objective OPF considering emissions based shunt FACTS. IECON Proc. (Ind. Electron. Conf.) 2012, 1337-1343. [CrossRef]

53. Selvakumar, A.I.; Thanushkodi, K. A new particle swarm optimization solution to nonconvex economic dispatch problems. IEEE Trans. POWER Syst. 2007, 22, 42-51. [CrossRef] 
54. The Electrical and Computer Engineering Department, I.I. of T. The Electrical and Computer Engineering Department, Illinois Institute of Technology, Data, The IEEE 118-Bus Test System Data. Available online: http:/ / motor.ece.iit.edu/data/JEAS_IEEE1 18.doc (accessed on 19 April 2021).

55. Bouchekara, H.R.E.H.; Abido, M.A.; Boucherma, M. Optimal power flow using Teaching-Learning-Based Optimization technique. Electr. Power Syst. Res. 2014, 114, 49-59. [CrossRef]

56. Pandiarajan, K.; Babulal, C.K. Fuzzy harmony search algorithm based optimal power flow for power system security enhancement. Int. J. Electr. Power Energy Syst. 2016, 78, 72-79. [CrossRef]

57. Bhattacharya, A.; Roy, P.K. Solution of multi-objective optimal power flow using gravitational search algorithm. IET Gener. Transm. Distrib. 2012, 6, 751. [CrossRef]

58. Radosavljević, J.; Klimenta, D.; Jevtić, M.; Arsić, N. Optimal Power Flow Using a Hybrid Optimization Algorithm of Particle Swarm Optimization and Gravitational Search Algorithm. Electr. Power Components Syst. 2015, 43, 1958-1970. [CrossRef]

59. Bouchekara, H.R.E.H.; Chaib, A.E.; Abido, M.A.; El-Sehiemy, R.A. Optimal power flow using an Improved Colliding Bodies Optimization algorithm. Appl. Soft Comput. J. 2016, 42, 119-131. [CrossRef]

60. Mohamed, A.-A.A.; Mohamed, Y.S.; El-Gaafary, A.A.M.; Hemeida, A.M. Optimal power flow using moth swarm algorithm. Electr. Power Syst. Res. 2017, 142, 190-206. [CrossRef]

61. Attia, A.F.; El Sehiemy, R.A.; Hasanien, H.M. Optimal power flow solution in power systems using a novel Sine-Cosine algorithm. Int. J. Electr. Power Energy Syst. 2018, 99, 331-343. [CrossRef] 